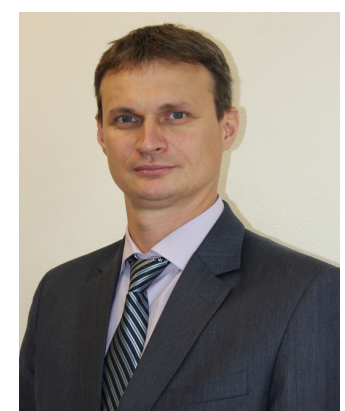

Линенко А.В.

Linenko A.V.

доктор технических наук, профессор,

декан энергетического факультета ФГБОУ ВО «Башкирский государственный

аграрный университет»,

$$
\text { 2. Уфа, }
$$

Российская Федеращия

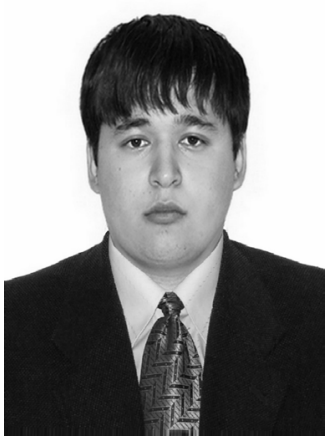

Азнагулов А.И.

Aznagulov A.I.

аспирант кафедры «Электрических

машин и электрооборудования»

ФГБОУ ВО «Башкирский государственный

аграрный университет», 2. Уфа,

Российская Федерачия

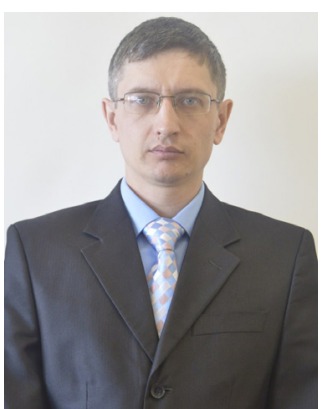

Сираев Ш.Ф.

Siraev Sh.F.

стариий преподаватеь кафедрь «Электроснабжения и применения электрической энергии в сельском хозяйстве» ФГБОУ ВО «Башкирский государственный аграрный университет»,

$$
\text { 2. Уфа, }
$$

Российская Федерация

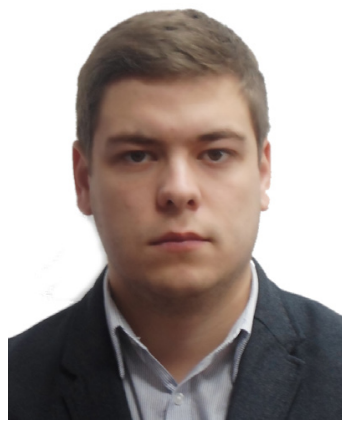

Лукьянов В.В.

Luk'janov V.V.

аспирант кафедры «Электрических

машин и электрооборудования»

ФГБОУ ВО «Башкирский государственный аграрный университет»,

$$
\text { 2. Уфа, }
$$

Российская Федерация

DOI:

Повысить производство продукции растениеводства можно за счет внедрения системы точного земледелия, где важным является обеспечить точность движения машинно-тракторного агрегата (MTA) до нескольких сантиметров по навигационным спутниковым системам. Такую точность может обеспечить подруливающее устройство, в котором электродвигатель постоянного тока через механический преобразователь по сигналам блока управления обеспечивает поворот рулевого колеса на требуемый угол. Наличие дополнительных механиче- 
ских связей между рулевым колесом и ротором электродвигателя негативно сказывается на точности управления агрегатом, надежности и стоимости подруливающего устройства. В работе предложен мехатронный модуль, состоящий из двух частей, который позволяет увеличить быстродействие автоматической системы управления, упростить конструкцию и снизить ее стоимость. В механической части мехатронного модуля использован бесколлекторный двигатель постоянного тока (БКДПТ), ротор которого является составной частью рулевого колеса. Изменение положения ротора является поворотом рулевого колеса без промежуточных механизмов. Позиционирование ротора осуществляется с помощью трех дискретных датчиков Холла, установленных на статоре. Разработана и реализована в программе DIP TRACE принципиальная схема драйвера БКДПТ, которая реализована на базе микроконтроллера Atmel AT90PWM3, представлена часть программного кода функции прерывания по датчикам Холла. Получена динамическая зависимость скорости вращения ротора двигателя при разных моментах сопротивления на рулевом колесе. Временная стабилизация частоты вращения не превышает 0,3 секунды.

Внедрение мехатронной системы для управления МТА с использованием навигационных систем позволит уменьшить эксплуатационные затраты (на семена - до 15 \%, на химикаты и топливо - не менее 10 \%), снизить утомляемость оператора и увеличить производительность труда (возможность работы в ночное время, а также в условиях плохой видимости). Простой монтаж подруливающего устройства обеспечивает быструю его установку на любую отечественную и импортную технику.

Ключевые слова: мехатронная система, подруливающее устройство, точное земледелие, параллельное вождение, машинно-тракторный агрегат, электропривод, бесколлекторный двигатель постоянного тока, датчик Холла, пид-регулятор, микроконтроллер.

\section{MECHATRONIC SYSTEM FOR AUTOMATIC CONTROL OF A MACHINE-TRACTOR UNIT WITH A SCREW-FREE ELECTRIC MOTOR}

It is possible to increase crop production by introducing a system of precision farming, where it is important to ensure the accuracy of movement of the machine-tractor unit (MTA) to a few centimeters in navigation satellite systems. Such accuracy can be provided by the thruster, in which the DC motor, through a mechanical converter, according to the signals of the control unit, ensures the steering wheel to turn to the required angle. The presence of additional mechanical connections between the steering wheel and the rotor of the electric motor adversely affects the accuracy of the control unit, the reliability and cost of thruster. The paper proposed a mechatronic module consisting of two parts, which allows you to increase the speed of the automatic control system, simplify the design and reduce its cost. In the mechanical part of the mechatronic module, a brushless DC motor is used, the rotor of which is an integral part of the steering wheel. Changing the position of the rotor is turning the steering wheel without intermediate mechanisms. The rotor is positioned using three discrete Hall sensors mounted on the stator. The DIP TRACE program has been developed and implemented in the BKDPT driver, which is based on the Atmel AT90PWM3 microcontroller, and presents a portion of the program code for the interrupt function by Hall sensors. The dynamic dependence of the rotation speed of the rotor of the engine at different points of resistance on the steering wheel The time stabilization of the rotation speed does not exceed 0.3 seconds.

The introduction of a mechatronic system for controlling the MTA using navigation systems will reduce operating costs (up to $15 \%$ for seeds, chemicals and fuel not less than 10\%), reduce operator fatigue and increase labor productivity (ability to work at night, as well as in bad conditions visibility). Simple installation of the thruster ensures its quick installation on any domestic and imported equipment.

Key words: mechatronic system; thruster; precision farming; parallel driving; machine and tractor unit; electric drive; brushless DC motor; Hall Sensor; PID-regulator; microcontroller. 
Практическое отсутствие цифровых технологий в сельском хозяйстве (менее $10 \%$ от всех технологических операций) является сдерживающим фактором повышения производства продукции. В системе точного земледелия необходимо обеспечить параллельное вождение машинно-тракторного агрегата (МТА) с высокой точностью (0-25 см) [2].

Одним из сдерживающих факторов повышения точности и надежности подруливающего устройства МТА является наличие механических подвижных составляющих в структуре его привода [3]. Механические составляющие (редукторы, механизм подвода электропривода к рулевому колесу) увеличивают себестоимость подруливающего устройства, значительно усложняют и сни- жают его точность, что сказывается на надежности.

Тенденция развития систем автоматического управления МТА заключается в повышении ее точности и надежности при одновременном уменьшении энергопотребления и снижении стоимости. Для решения поставленных вопросов предлагается оснастить MTA мехатронным модулем, который включает в себя аппаратно-программный комплекс с микропроцессорной системой управления, a также бесколлекторный электропривод рулевого колеса, в котором ротор является валом рулевого колеса, а движение МТА осуществляется по спутниковым сигналам системы ГЛОНАСС (рис. 1).

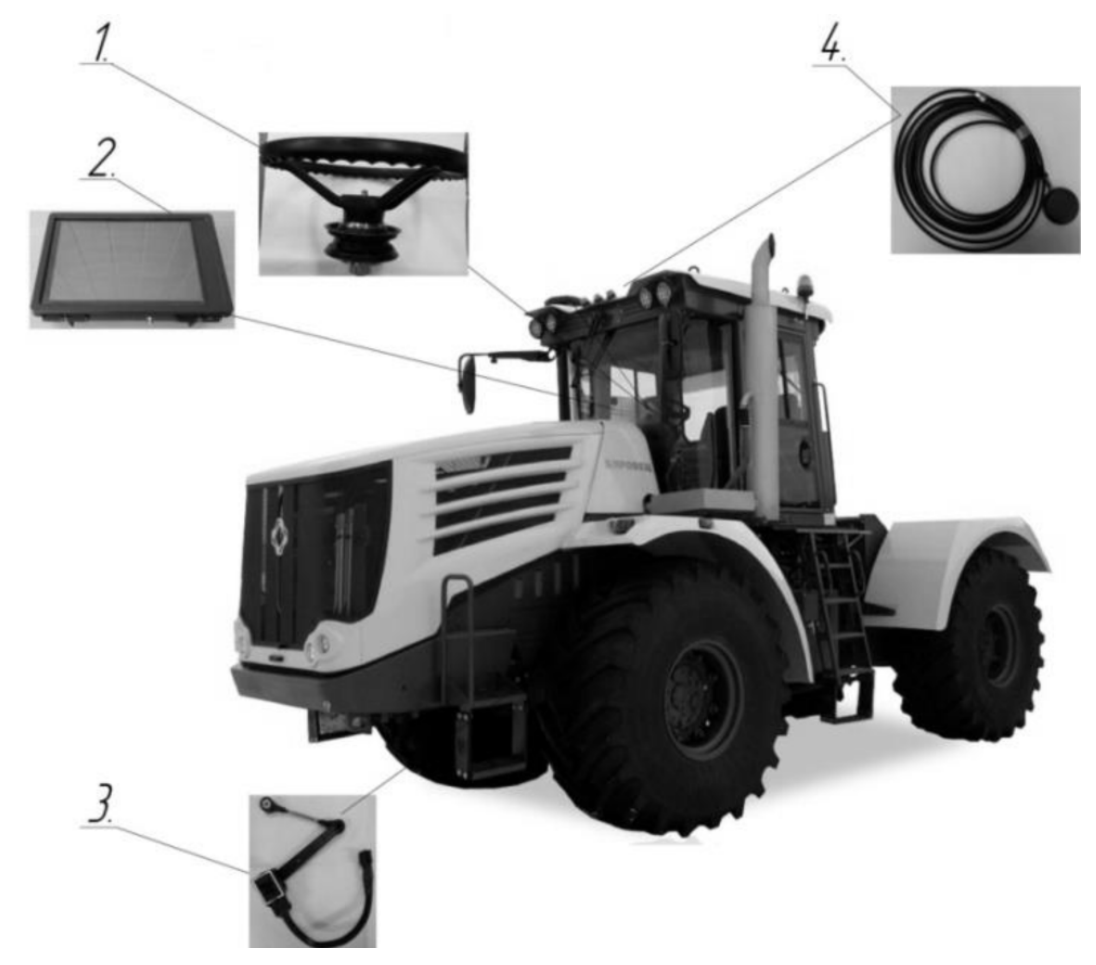

Рисунок 1. Расположение оборудования мехатронной системы для управления машинно-тракторным агрегатом с использованием ГЛОНАСС навигации: 1 - подруливающее устройство; 2 - курсоуказатель; 3 - датчик угла поворота колес; 4 - высокоточная антенна с магнитным основанием

Мехатронная система управления МТА это система, образованная конструктивным слиянием электрической машины с рабочим органом (рулевым колесом) для осуществления заданного движения МТА под управлением интеллектуальной системы.

В качестве воздействующего механизма на рулевое колесо в структуре мехатронного модуля использован бесколлекторный двигатель постоянного тока (БКДПТ) с датчиками
Холла (рис. 2). Статор 4 БКДПТ жестко закреплен на рулевой колонке 1 . Рулевое колесо 10 жестко соединено с ротором 7 БКДПТ, который, в свою очередь, также зафиксирован на рулевой колонке посредством подшипника 6 с возможностью вращения. 


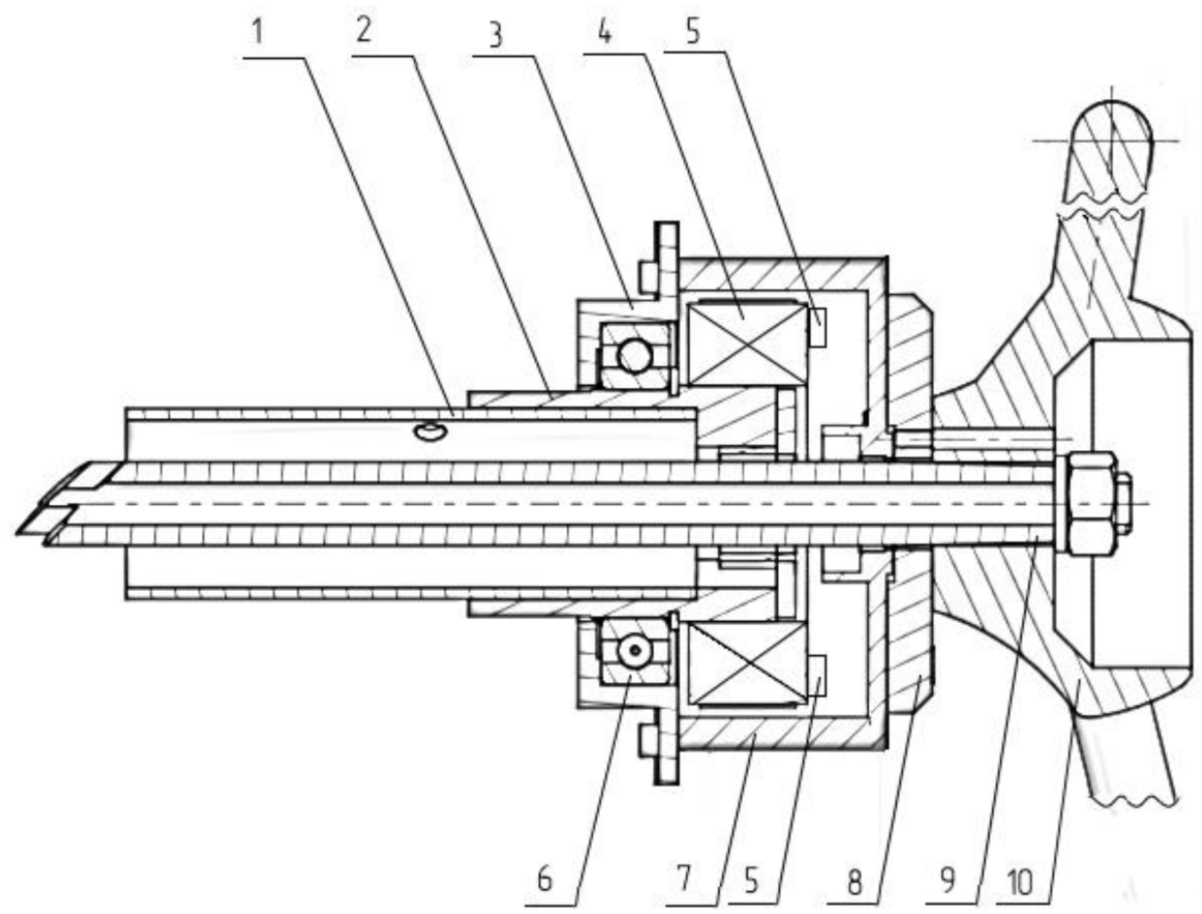

Рисунок 2. Механическая часть мехатронного модуля подруливающего устройства с БКДПТ: 1 - рулевая колонка, 2 - фланец сердечника статора, 3 - корпус подшипника, 4 - статор, 5 - датчики Холла, 6 - подшипник, 7 - ротор, 8 - фланец ротора, 9 - вал рулевого колеса, 10 - рулевое колесо

БКДПТ для мехатронного модуля является наиболее подходящим типом электропривода постоянного тока, в котором регулирование скорости и момента вращения осуществляется подводимым напряжением и углом опережения включения фаз. Он обладает регулировочными качествами машин постоянного тока и надежностью систем переменного тока [1].

БКДПТ по принципу действия и рабочим характеристикам близок к коллекторному двигателю постоянного тока, а благодаря исключению коллектора имеет высокую надежность и долговечность, требует меньших расходов на обслуживание. Кроме того, БКДПТ имеет возможность осуществления бесконтактного реверса без вмешательства в силовые цепи привода (увеличением угла опережения либо реверсом двух фаз в цепях датчика положения ротора).

Конструктивно БКДПТ состоит из ротора (1) с постоянными магнитами и статора (2) с обмотками, которые соединяются звездой. На статоре имеются датчики Холла, необходимые для определения положения ротора относительно статора. Статор, состоящий из нескольких секций, позволяет стабилизировать вращающий момент на низких оборотах работы двигателя.

Управление осуществляется по принципу частотного регулирования, т.е. управление инвертором преобразователя частоты осуществляется в функции углового положения ротора двигателя. Программная реализация данного подхода содержит контур управления скоростью с помощью ПИДрегулятора. Такой регулятор состоит из трех звеньев, каждый из которых характеризуется собственным коэффициентом передачи: $\mathrm{K}_{\text {п }}$ - коэффициент передачи пропорционального звена, $\mathrm{K}_{\text {и }}$ - коэффициент передачи интегрирующего звена и $\mathrm{K}_{д}-$ коэффициент передачи дифференцирующего звена (рис. 3) [4].

Отклонение требуемой скорости от фактической («ошибка рассогласования») обрабатывается каждым из звеньев, результат операций суммируется и подается на двигатель для получения желаемой частоты вращения.

Коэффициент К плияет на длительность переходного процесса, коэффициент $\mathrm{K}_{\text {и }}$ позволяет подавить статические ошибки, а $\mathrm{K}_{\text {д }}$ используется для стабилизации положения ротора. 


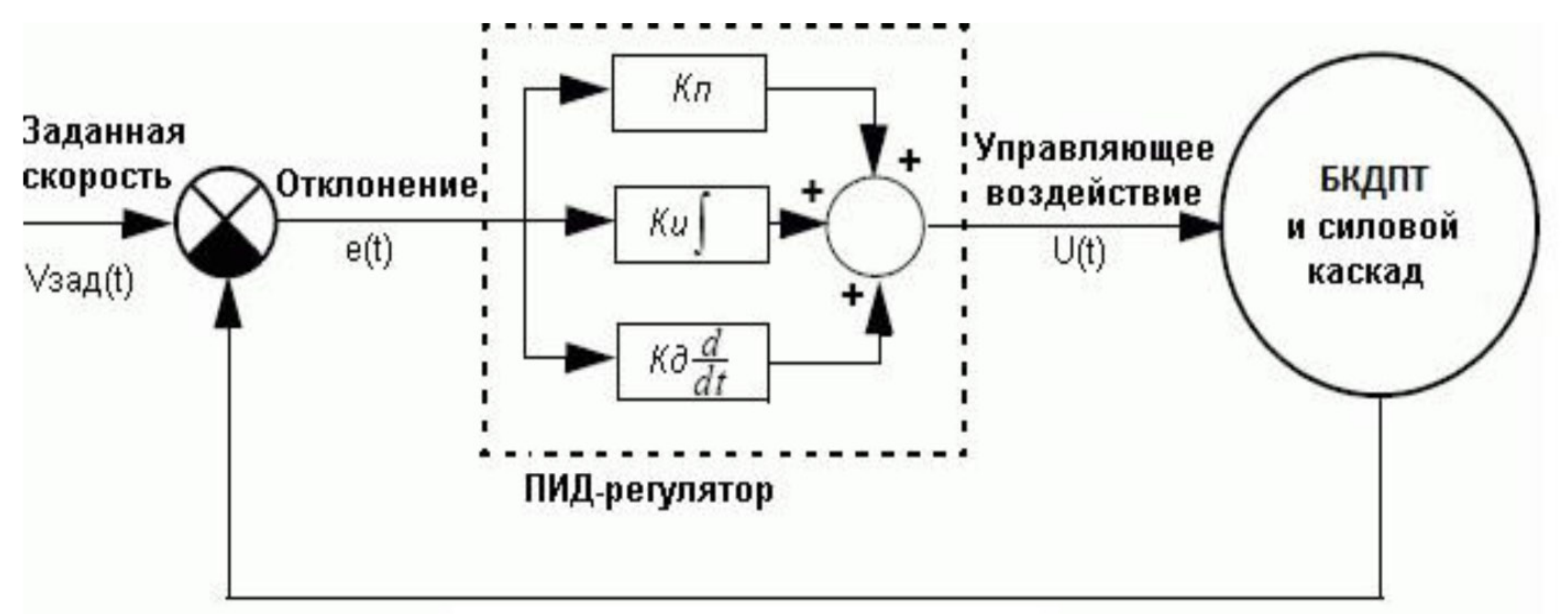

Рисунок 3. Структурная схема ПИД-регулятор БКДПТ

Как показано на функциональной схеме (рис. 4), контроллер содержит 3 силовых каскада. Каждый силовой каскад работает как широтно-импульсный модулятор с двумя выходными сигналами. Во избежание воз- никновения короткого замыкания в силовых каскадах поддерживается возможность управления задержкой момента включения с помощью драйвера двигателя для каждой пары силовых ключей.

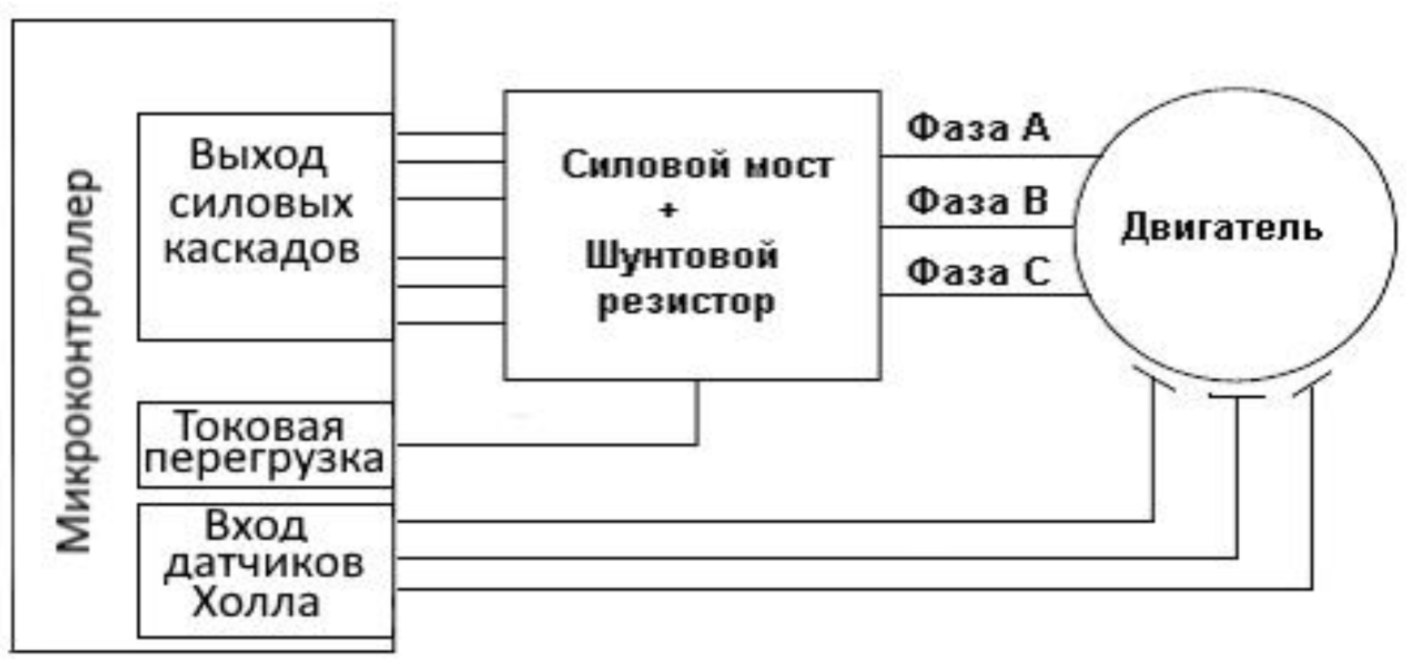

Рисунок 4. Функциональная схема управления БКДПТ

Для измерения тока используются два дифференциальных канала с программируемым усилительным каскадом $\left(\mathrm{K}_{\mathrm{y}}=10\right)$. Номинал шунтового резистора для наиболее полного охвата диапазона преобразования составляет 0,05 Ом. Сигнал «Токовая перегрузка» формируется внешним компаратором. Пороговое напряжение компаратора регулируется с помощью внутреннего цифроаналогового преобразователя.

Для управления БКДПТ используется силовой каскад, состоящий из 3 полумостов, каждое плечо которого управляется отдельным драйвером. Принципиальная схема драйвера составлена в программе DIPTRACE (рис. 5). 


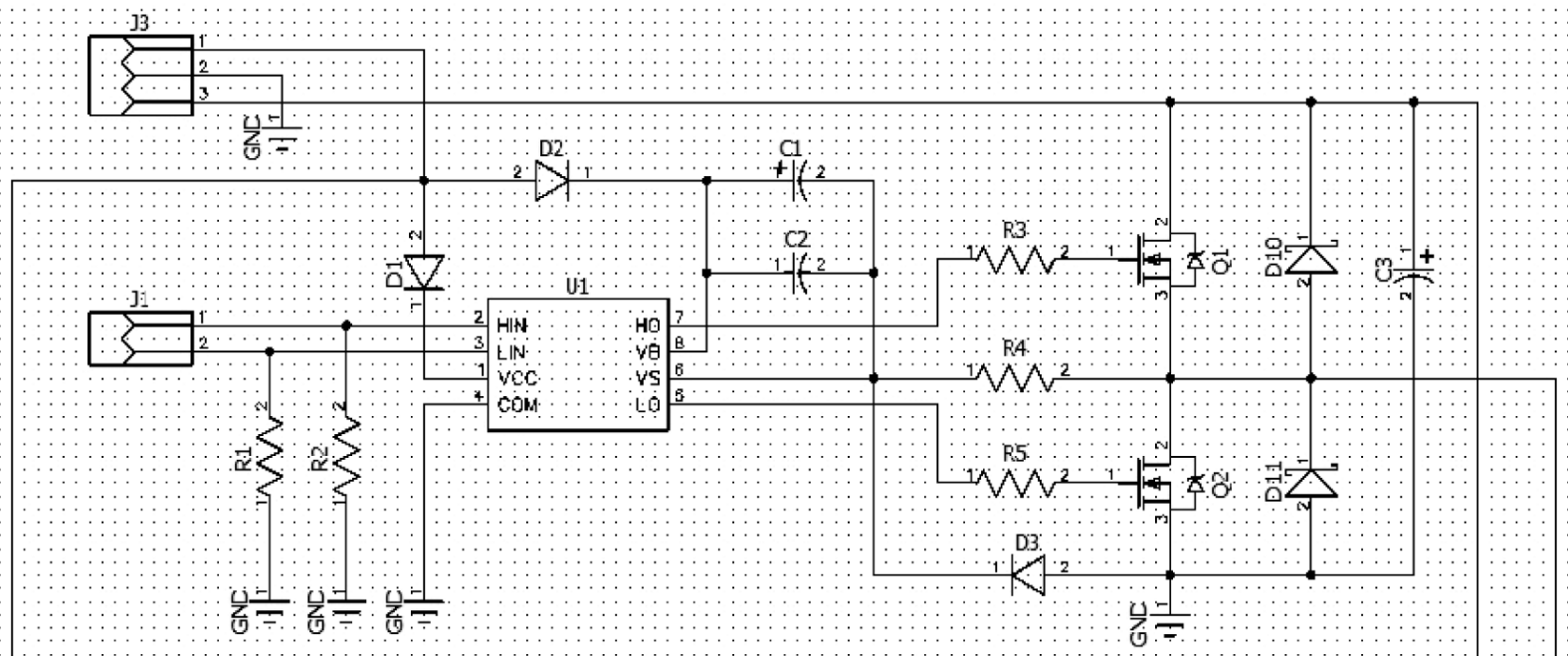

Рисунок 5. Принципиальная схема драйвера БКДПТ

Рассматриваемый БКДПТ работает на дискретных датчиках Холла [5]. На один электрический оборот датчики Холла выдают комбинацию из 3 логических сигналов в виде меандры сдвинутых по фазе на 120 электрических градусов. Для управления фазами двигателя используется разнополярная 6-тактная парная коммутация, порядок коммутации представлен в таблице 1. Переключение фаз происходит через каждые 60 электрических градусов.

Таблица 1. Порядок коммутация ключей

\begin{tabular}{|l|l|}
\hline Значение датчиков Холла & Фаза \\
\hline 101 & A-B \\
\hline 001 & A-C \\
\hline 011 & B-C \\
\hline 010 & B-A \\
\hline 110 & C-A \\
\hline 100 & C-B \\
\hline
\end{tabular}

Система управления БКДПТ подруливающего устройства разработана на базе микроконтроллера фирмы Atmel. Часть программного кода (функция прерывания по датчикам Холла) представлена в листинге 1.

В результате экспериментального определения коэффициентов ПИД-регулятора получен оптимальный режим работы БКДПТ для подруливающего устройства. Динамическая зависимость скорости вра- щения ротора БКДПТ, при разных значениях момента силы сопротивления на рулевом колесе, полученная в результате экспериментального моделирования работы подруливающего устройства, представлена на рисунке 6. 
Листинг 1. Функция прерывания по датчикам Холла

// Обработчик внешнего прерывания INTO.

ISR (INTO_vect) \{

delāy_us (100);

$\overline{\text { iff }}((\mathrm{PI} \overline{\mathrm{N}} \mathrm{D} \&(1<\mathrm{PD} 2))==0)\{$

_delay_us (100);

// Крутим против часовой стрелки

if $((\operatorname{PIND} \&(1<<\mathrm{PD} 1))==0)$

\{

if (motor pwm != START PWM) motor pwm $-=5$;

// Уменьшаем шим

\}

// Крутим по часовой стрелке

else

\{

if(motor_pwm $!=255$ ) motor_pwm $+=5$;

/ / Увеличиваемшим

\}

\} \}

Как видно из графика, скорость вращения ротора БКДПТ стабилизируется на требу-

секунд, с момента воздействия тормозяемом значении в течение не более 0,3

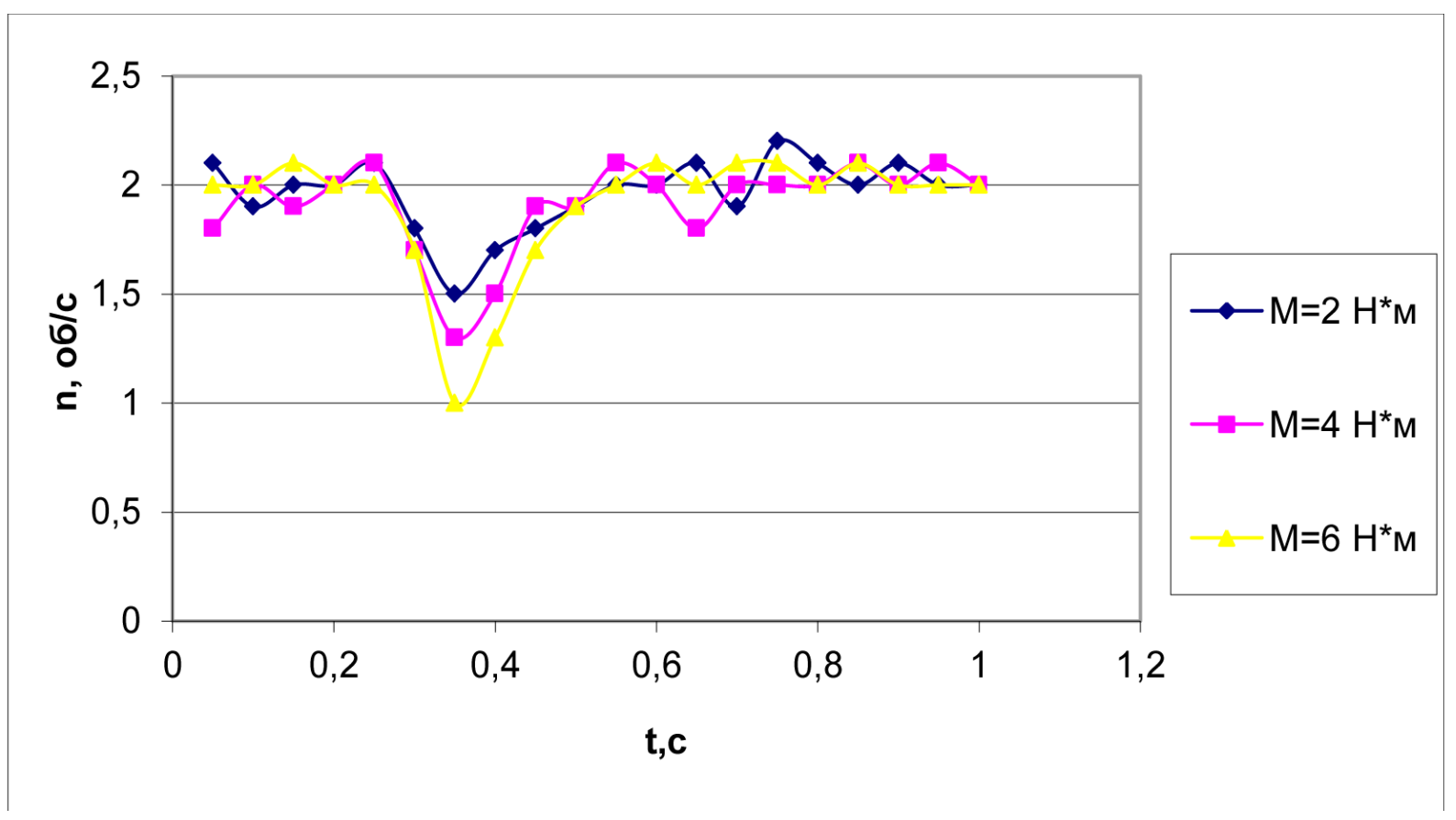

Рисунок 6. Динамическая зависимость скорости вращения ротора БКДПТ при разных значения тормозящего момента на рулевом механизме

График, представленный на рисунке 7, показывает, что «время реакции» предсекунд, что более чем достаточно для ложенной системы для подруливающих подруливающих устройств. устройств составляет не более 0,25 


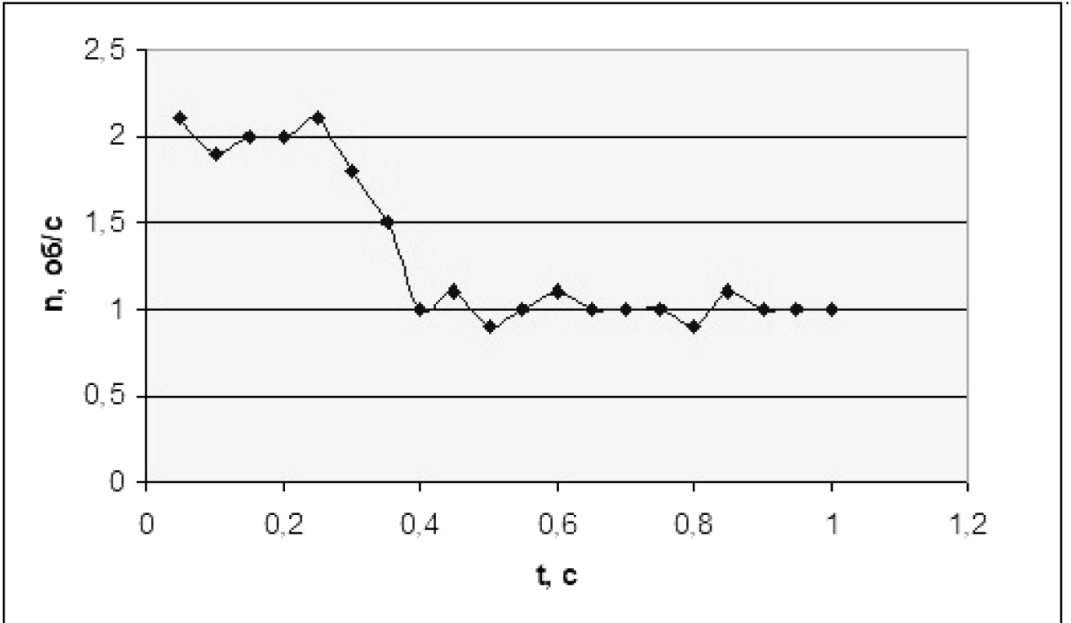

Рисунок 7. Пример переходного процесса изменения скорости вращения ротора БКДПТ при подруливании

Предложен мехатронный модуль для автоматического управления МТА, который включает механическую и интеллектуальную системы. Механическая система представлена бесколлекторным двигателем постоянного тока с датчиками Холла, причем статор двигателя жестко установлен на неподвижной рулевой колонке трактора, а его ротор соединен с рулевым колесом. В интеллектуальную систему входит аппаратно-программный комплекс с микропроцессорным управлением. Аппаратная часть реализована с микропроцессором фирмы Atmel.

\section{Список литературы}

1. Ильинский Н.Ф. Перспективы развития регулируемого электропривода. Электричество. - 2003. - № 2. - С. 3-7.

2. Труфляк Е.В. Основные элементы системы точного земледелия. - Краснодар: КубГАУ, 2016. - 39 с.

3. Патент на полезную модель № 183287 Исполнительное устройства для автоматического управления машино-тракторным агрегатом / А.В. Линенко, А.И. Азнагулов, М.М. Ямалетдинов. № 2018114392; заявл. 18.04.18; опубл. 17.09.18 с.

4. Дорф Р., Бишоп Р. Современные системы управления / Пер. с англ. Б.И. Копылова. М.: Лаборатория базовых знаний, 2002. - 832 c.

5. Герасимов В.Г., Кузнецов Э.В., Николаева О.В. Электротехника и электроника. - Кн. 2. Электромагнитные устройства и электрические машины. - М.: Энергоатомиздат, 1997. — 288 с.
Мехатронный модуль может быть установлен на любой МТА и обеспечивает непосредственное воздействие на рулевое колесо, минуя различного рода преобразователи. Такой подход позволяет повысить точность и надежность системы управления, а также снизить ее себестоимость. Исследование системы показало ее работоспособность, продолжительность переходных процессов на статоре не более 0,25 с.

\section{References}

1. Il'inskij N.F. Perspektivy razvitija regulirujemogo elektroprivoda // Elektrichestvo. - 2003. - № 2. - C. 3-7.

2. Trufljak E.V. Osnovnye elementy sistemy tochnogo zemledelija. - Krasnodar: KubGAU, 2016. $-39 \mathrm{p}$.

3. Patent na poleznuju model' № 183287 Ispolnitel'noje ustrojstva dlja avtomaticheskogo upravlenija mashino-traktornym agregatom / A.V. Linenko, A.I. Aznagulov, M.M. Jamaletdinov. № 2018114392; zajavl. 18.04.18; opubl. 17.09.18 p.

4. Dorf P., Bishop R. Sovremennyje sistemy upravlenija / Per. s angl. B.I. Kopylova. - M.: Laboratorija bazovyh znanij, 2002. - $832 \mathrm{p}$.

5. Gerasimov V.G., Kuznecov Je. V., Nikolaeva O.V. Elektrotehnika i elektronika. Vol. 2. Elektromagnitnyje ustrojstva i elektricheskije mashiny. - M.: Energoatomizdat, 1997. — $288 \mathrm{p}$. 